\title{
Thermodynamic Analysis of a Cascade Refrigeration System
}

\author{
R. KARAALI* \\ ${ }^{a}$ Department of Mechanical Engineering, Bayburt University, 69000 Bayburt, Turkey
}

\begin{abstract}
There is a need for cooling by using the waste heat energy in food industry. Absorption cycles can be driven by waste thermal, geothermal, solar or industrial processes energies. In this study, cascade refrigeration system is thermodynamically modeled, and analyzed by using first law of thermodynamics, and exergy method. Thermodynamic properties such as pressure, temperature, entropy, enthalpy, exergy, mass flow rate in each stream are calculated for $50,75,100^{\circ} \mathrm{C}$ and for $0.8,1.0$, and $1.5 \mathrm{MPa}$ pump pressure. A computer program is used that was prepared in FORTRAN by the author for the analyses. It is found that the compression-absorption cascade cooling cycle is appropriate for most of the kind of waste heat applications. Increase of the generator inlet heat temperature increases the generator inlet heat, the absorber outlet heat and the condenser 2 outlet heat energies and decreases the coefficient of performance of the absorption and the overall cycles. The generator heat decreases with increase of the pump pressure. Also increase of the pump pressure decreases the coefficient of performance of the absorption and the overall cycles. Increase of the pump pressure and the generator temperature decreases the exergetic coefficient of performance. Increase of the generator temperature and pump pressure increases the generator inlet exergy. It is concluded that increase of the generator temperature and the pump pressure increases the total destructed exergy of the cycle.
\end{abstract}

DOI: 10.12693/APhysPolA.130.101

PACS/topics: 88.05.Sv, 88.10.cn

\section{Introduction}

Waste heat is an important energy resource for many industrial applications, because of the environmental problems and economical use of energy. Using waste heat is one of the best solutions especially for cooling applications. To reduce the demand on electricity supply the absorption refrigeration systems are very helpful. By using inexpensive geothermal, biomass, waste heat, or solar energy sources absorption cooling can be done. Cascaded refrigeration systems maintain the advantages of both vapor compression and absorption refrigeration systems. Because the synthetic refrigerants (CFC's, HFC's) have environmental problems, natural substances such as water-lithium bromide or ammonia-water pair started to be used for cooling purposes. Ammonia-water solutions are available refrigerants for cooling systems. For using low temperatures heat sources, the most common working fluids for cooling are water-lithium bromide or ammonia-water solutions [1]. The main advantage of the ammonia-water cooling is that ammonia can evaporate at lower temperatures. The structure of the system is more complex than the compression vapour cycles. Also its coefficient of performance is lower than the other cooling systems.

The thermodynamic analysis of an absorption-vapor compression cascade cooling system is done in this study. One of study in literature on the comparison of $\mathrm{NH}_{3}-$ $\mathrm{H}_{2} \mathrm{O}, \mathrm{NH}_{3}-\mathrm{LiNO}_{3}$ and $\mathrm{NH}_{3}-\mathrm{NaSCN}$ absorption refrigeration systems by using energy analysis method has been

*e-mail: rabikar@gmail.com done by Sun [2]. He found that for temperatures below $-10^{\circ} \mathrm{C}$ the performance of the ammonia-water is better than the ammonia-lithium nitrate and the ammoniasodium thiocyanate. However the ammonia-lithium nitrate and the ammonia-sodium thiocyanate give better performance than the ammonia-water over $-10^{\circ} \mathrm{C}$ temperatures [2]. Seara et al. have found that the use of $\mathrm{CO}_{2}$ or $\mathrm{NH}_{3}$ as refrigerants in compression stage does not affect significantly the operating conditions of the absorption stage and they explained in their study on energy analysis of compression-absorption cascade refrigeration systems [3]. Cimsit and Ozturk have found that $48-51 \%$ less electric energy is consumed in compressionabsorption cascade refrigeration cycles than the classic vapor compression cycles for the same cooling capacity [4]. Jain et al. showed that electric power consumption in vapor compression absorption $\left(\mathrm{LiBr}-\mathrm{H}_{2} \mathrm{O}\right)$ cascaded refrigeration system is reduced by $61 \%$ and coefficient of performance ( $\mathrm{COP}$ ) of compression section is improved by $155 \%$ as compared with equivalent vapor compression refrigeration system [5]. Also Jain et al. have studied on thermo-economic optimization of this cycle and found that this cycle decreases the total annual cost by $11.9 \%$ [6]. In addition, Jain et al., in their recent study have analyzed thermo-economic and environmental optimization of this cycle and found that the multi objective optimization is better than the thermoeconomic optimization [7]. Xu et al. present a novel absorption compression cascade refrigeration system which can reach an evaporating temperature $-170^{\circ} \mathrm{C}$ in their study. They found in their theoretical energy analysis and experimental study that the performance of compression subsystem is improved and comparing theoretical data with experimental data the variation tendency were similar [8]. Chen et al. proposes a novel heat driven 
absorption compression refrigeration system which can produce $46 \%$ more cooling energy than the reference system and can reach a temperature as low as $-60^{\circ} \mathrm{C}[9]$. Mehrpooya et al. in their study introduced a novel mixed fluid cascade natural gas liquefaction process configuration using absorption refrigeration system obtained by replacement of some vapor compression refrigeration cycles and they found that $30 \%$ reduction in power consumption could be achieved [10].

To obtain the exergetic analysis of the compressionabsorption cascade refrigeration systems and the exergetic destructions in the components which use ammonia-water solutions is the goal of this study.

\section{Description and analysis of the cycle}

The pure accepted ammonia, the strong ammoniawater solution and the weak ammonia-water solution are the three kinds of working fluids used in the ammoniawater cycles. The remaining solution is accepted as the weak ammonia-water solution that in the boiling process of the ammonia vapor leaves from the strong ammoniawater solution. In the analysis these assumptions have been done; the cycle is under steady state conditions, ammonia-water solutions are in the equilibrium for their pressures and temperatures, ammonia-water mixtures are in the states of Table I as given, the pressure losses in the cycle are neglected, the ammonia vapor is condensed at the outlet of the condenser 2 and the isentropic efficiency of the compressor is $\eta_{\text {is }}=0.90$.

For the cycles use as a working fluid the thermodynamic properties of ammonia-water solution are very important. A thermodynamic design data and optimum design maps for absorption refrigeration systems has been proposed by Sun, in his study. But the results of the equations proposed by him are for a limited range and difficult to use [11]. Calculating the enthalpy and the entropy values of the ammonia-water mixtures can be done with three methods. Those are the El-Sayed and Tribus method, the Gibbs free energy method, and the Park and Sonntag method [2]. In this study, the tables of the enthalpy values of the ammonia-water mixtures are taken from Ref. [12] which is derived from the Park and Sonntag method which uses the Helmholtz free energy equations. In Ref. [12], for pure ammonia vapor at 1 atm pressure and at $195.495 \mathrm{~K}$ temperature are taken as the reference state values which are $u_{0}=0, h_{0}=0$ and $s_{0}=0$. However, in this study for the sake of simplicity and understandability, for the mixture of water-ammonia, the reference state values are taken at $100 \mathrm{kPa}$ pressure and $-50{ }^{\circ} \mathrm{C}$ temperature as $h_{0}=118.47 \mathrm{~kJ} / \mathrm{kg}$ and $s_{0}=0.5659 \mathrm{~kJ} /(\mathrm{kg} \mathrm{K})$

TABLE I

Mass, energy and exergy equations $[13,14]$ for each component and for overall cycle

\begin{tabular}{|c|c|c|c|}
\hline Component & Mass equation & Energy equation & Exergy equation \\
\hline pump & $\dot{m}_{1}=\dot{m}_{2}$ & $\dot{W}_{P}=\dot{m}_{1}\left[h_{2}-h_{1}\right)$ & $\begin{array}{l}\dot{E}_{1}=\dot{m}_{1}\left[h_{1}-h_{0}-T_{0}\left(s_{1}-s_{0}\right)\right] \\
\dot{E}_{2}=\dot{m}_{2}\left[h_{2}-h_{0}-T_{0}\left(s_{2}-s_{0}\right)\right]\end{array}$ \\
\hline heat exchanger & $\begin{array}{l}\dot{m}_{2}=\dot{m}_{3} \\
\dot{m}_{4}=\dot{m}_{5}\end{array}$ & $\dot{m}_{2}\left(h_{3}-h_{2}\right)=\dot{m}_{4}\left[h_{4}-h_{5}\right)$ & $\begin{array}{l}\dot{E}_{3}=\dot{m}_{3}\left[h_{3}-h_{0}-T_{0}\left(s_{3}-s_{0}\right)\right] \\
\dot{E}_{4}=\dot{m}_{4}\left[h_{4}-h_{0}-T_{0}\left(s_{4}-s_{0}\right)\right] \\
\dot{E}_{5}=\dot{m}_{5}\left[h_{5}-h_{0}-T_{0}\left(s_{5}-s_{0}\right)\right]\end{array}$ \\
\hline generator & $\dot{m}_{3}=\dot{m}_{7}+\dot{m}_{4}$ & $\dot{m}_{3} h_{3}+\dot{Q}_{\mathrm{G}}=\dot{m}_{4} h_{4}+\dot{m}_{7} h_{7}$ & $\dot{E}_{7}=\dot{m}_{7}\left[h_{7}-h_{0}-T_{0}\left(s_{7}-s_{0}\right)\right]$ \\
\hline condenser 2 & $\dot{m}_{7}=\dot{m}_{8}$ & $\dot{m}_{8} h_{8}+\dot{Q}_{C 2}=\dot{m}_{7} h_{7}$ & $\dot{E}_{8}=\dot{m}_{8}\left[h_{8}-h_{0}-T_{0}\left(s_{8}-s_{0}\right)\right]$ \\
\hline evaporator 2 & $\dot{m}_{9}=\dot{m}_{10}$ & $\dot{m}_{9} h_{9}+\dot{Q}_{C 1}=\dot{m}_{10} h_{10}$ & $\begin{array}{l}\dot{E}_{9}=\dot{m}_{9}\left[h_{9}-h_{0}-T_{0}\left(s_{9}-s_{0}\right)\right] \\
\dot{E}_{10}=\dot{m}_{10}\left[h_{10}-h_{0}-T_{0}\left(s_{10}-s_{0}\right)\right]\end{array}$ \\
\hline absorber & $\dot{m}_{1}=\dot{m}_{6}+\dot{m}_{10}$ & $\dot{Q}_{A}=\dot{m}_{10} h_{10}+\dot{m}_{6} h_{6}-\dot{m}_{1} h_{1}$ & $\dot{E}_{6}=\dot{m}_{6}\left[h_{6}-h_{0}-T_{0}\left(s_{6}-s_{0}\right)\right]$ \\
\hline condenser 1 & $\dot{m}_{11}=\dot{m}_{12}$ & $\dot{m}_{12} h_{12}+\dot{Q}_{C 1}=\dot{m}_{11} h_{11}$ & $\begin{array}{l}\dot{E}_{11}=\dot{m}_{11}\left[h_{11}-h_{0}-T_{0}\left(s_{11}-s_{0}\right)\right] \\
\dot{E}_{12}=\dot{m}_{12}\left[h_{12}-h_{0}-T_{0}\left(s_{12}-s_{0}\right)\right]\end{array}$ \\
\hline evaporator 1 & $\dot{m}_{13}=\dot{m}_{14}$ & $\dot{m}_{13} h_{13}+\dot{Q}_{E 1}=\dot{m}_{14} h_{14}$ & $\dot{E}_{13}=\dot{m}_{13}\left[h_{13}-h_{0}-T_{0}\left(s_{13}-s_{0}\right)\right]$ \\
\hline compressor & $\dot{m}_{14}=\dot{m}_{11}$ & $\dot{W}_{C}=\dot{m}_{14}\left[h_{11}-h_{14}\right) / \eta_{C}$ & $\dot{E}_{14}=\dot{m}_{14}\left[h_{14}-h_{0}-T_{0}\left(s_{14}-s_{0}\right)\right]$ \\
\hline overall cycle & \multicolumn{2}{|c|}{$\begin{array}{l}\dot{m}_{\text {solution }}=\dot{m}_{\text {Ammonia }}+\dot{m}_{\text {water }} \\
\dot{m}_{\text {sol }} X_{\text {sol }}=\dot{m}_{\text {Ammonia }} X_{\text {Ammonia }}+\dot{m}_{\text {water }} X_{\text {water }} \\
\left(\dot{Q}_{\mathrm{G}}+\dot{Q}_{\mathrm{E} 1}+\dot{W}_{\mathrm{C}}+\dot{W}_{\mathrm{P}}\right)_{\text {inlet energy }}= \\
\left(\dot{Q}_{\mathrm{A}}+\dot{Q}_{\mathrm{C} 2}\right)_{\text {outlet energy }} \\
\text { COP of the absorption section, } \\
C O P_{\mathrm{AB}}=\dot{Q}_{\mathrm{E} 2} / \dot{Q}_{\mathrm{G}} \\
\text { COP of the compression section, } \\
\text { COP }=\dot{Q}_{\mathrm{E} 1} / \dot{W}_{\mathrm{C}} \\
\text { COP of the overall cycle, } \\
\text { COP }=\dot{Q}_{\mathrm{E} 1} /\left(\dot{W}_{\mathrm{C}}+\dot{Q}_{\mathrm{G}}\right) \\
T_{\mathrm{E} 1}=\frac{T_{13}+T_{14}}{2}, T_{\mathrm{E} 2}=\frac{T_{9}+T_{10}}{2} \\
\dot{E}_{\mathrm{E} 1}=\dot{Q}_{\mathrm{E} 1}\left(1-\frac{T_{0}}{T_{\mathrm{E} 1}}\right)\end{array}$} & $\begin{array}{l}\text { exergetic COP of the overall cycle, } \\
\text { ECOP }{ }_{\mathrm{OC}}=\frac{\dot{Q}_{\mathrm{E} 1}\left(1-\frac{T_{0}}{T_{\mathrm{E} 1}}\right)}{\dot{W}_{\mathrm{C}}+\dot{Q}_{\mathrm{G}}\left(1-\frac{T_{0}}{T_{\mathrm{G}}}\right)} \\
\dot{E}_{\mathrm{E} 2}=\dot{Q}_{\mathrm{C} 1}\left(1-\frac{T_{0}}{T_{\mathrm{E} 2}}\right) \\
\dot{E}_{\mathrm{G}}=\dot{E}_{4}+\dot{E}_{7}-\dot{E}_{3} \\
\dot{E}_{\mathrm{D}, \mathrm{A}}=\dot{E}_{10}+\dot{E}_{6}-\dot{E}_{1} \\
\dot{E}_{\mathrm{D}, \mathrm{C} 2}=\dot{E}_{7}-\dot{E}_{8} \\
\dot{E}_{\mathrm{D}, \mathrm{HE}}=\dot{E}_{4}+\dot{E}_{2}-\dot{E}_{3}-\dot{E}_{5} \\
\dot{E}_{\mathrm{D}, \mathrm{E} 2}=\dot{E}_{9}+\dot{E}_{\mathrm{E} 2}-\dot{E}_{12} \\
\dot{E}_{\mathrm{D}, \mathrm{C} 1}=\dot{E}_{11}-\dot{E}_{12}-\dot{E}_{\mathrm{E} 2}\end{array}$ \\
\hline
\end{tabular}


which is given in Ref. [12]. The reference state values for refrigerant $134 \mathrm{a}$ are taken at $51.64 \mathrm{kPa}$ pressure and $40^{\circ} \mathrm{C}$ temperature as $h_{0}=0 \mathrm{~kJ} / \mathrm{kg}$ and $s_{0}=0 \mathrm{~kJ} /(\mathrm{kg} \mathrm{K})$ which is given in Ref. [13].

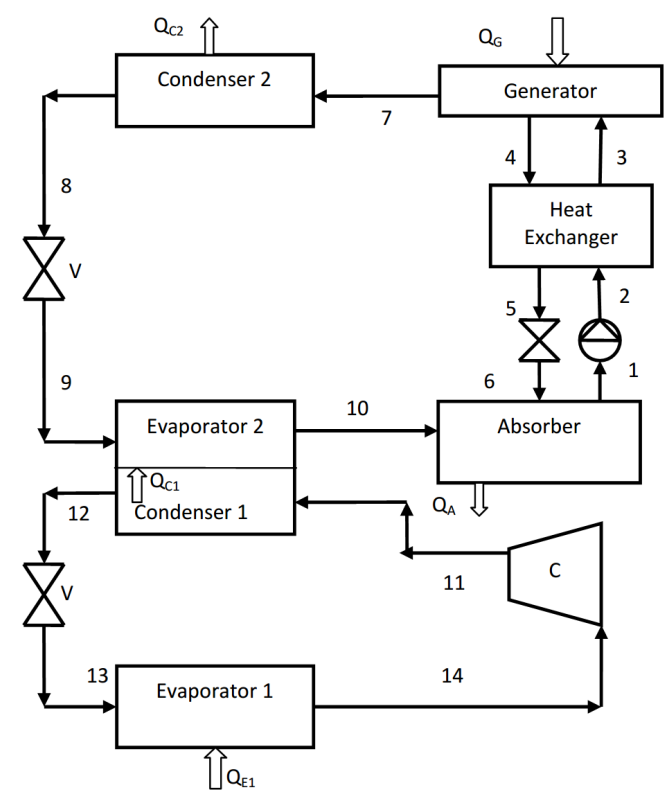

Fig. 1. Compression-absorption cascade cooling cycle.

The strong solution of $\mathrm{NH}_{3}-\mathrm{H}_{2} \mathrm{O}$ is pumped through the heat exchanger from the absorber. The high-pressure mixture enters the generator after heating in heat exchangers. The hot ammonia vapor is condensed in the condenser and the weak solution is sent back to the absorber after giving its some heat energy in the heat exchanger. In the absorber the strong solution is obtained by absorption the ammonia vapor. The ammonia as a saturated liquid after the condenser passes through an expansion valve. After the expansion valve the fluid passes through the evaporator.

In the evaporator liquid ammonia is evaporated by using the heat of the condenser of the vapour compression cycle. The cold vapour then enters the absorber, where it is mixed with the hot solution and is absorbed. At the vapour compression section the vapour fluid of R134-a is compressed to the high pressure at the compressor and then enters to the condenser. The vapour is condensed in the condenser and then the pressure of the liquid refrigerant is reduced in the expansion valve and then enters into evaporator.

There is no mass inlet or outlet of the cycle so that the cycle is a close cycle. The thermodynamic analysis of the cycle that is given in Fig. 1, will be done by using the thermodynamic modeling of the cycle for each component and for overall cycle. The mass, energy, stream exergy, destructed exergy, exergy of the components, COP, and exergetic coefficient of performance (ECOP) equations used in modeling and calculations are given in Table I.

\section{Results and discussion}

The temperature of most of the kinds of waste heat applications is over $50^{\circ} \mathrm{C}$. The temperature of the heat given into the boiler is taken as $50^{\circ} \mathrm{C}, 75^{\circ} \mathrm{C}, 100^{\circ} \mathrm{C}$ and this means that the compression-absorption cascade cooling cycle is appropriate for most of the kinds of waste heat applications. The power spends for the refrigeration systems can be decreased by about $30-50 \%$ by using this waste heat in absorption cooling system integrated with refrigeration systems.

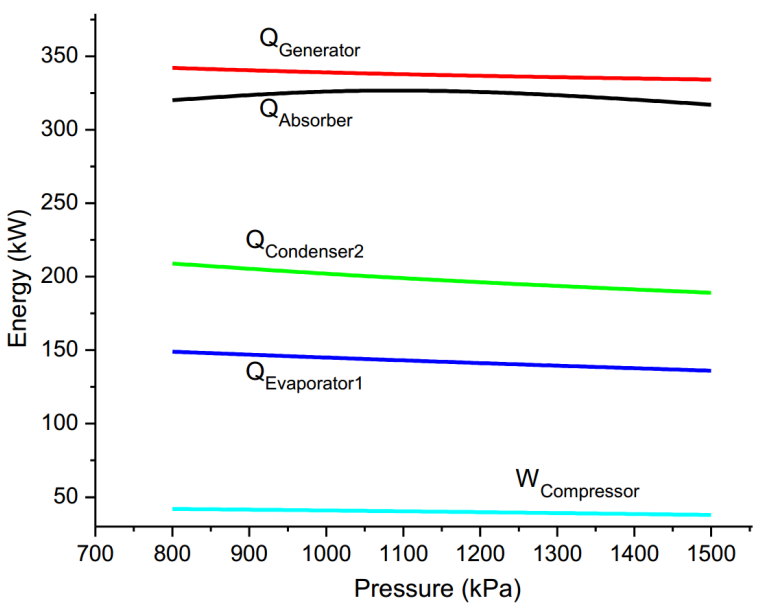

Fig. 2. Variation of energy with pressure of the cycle for $75^{\circ} \mathrm{C}$ temperature of generator.

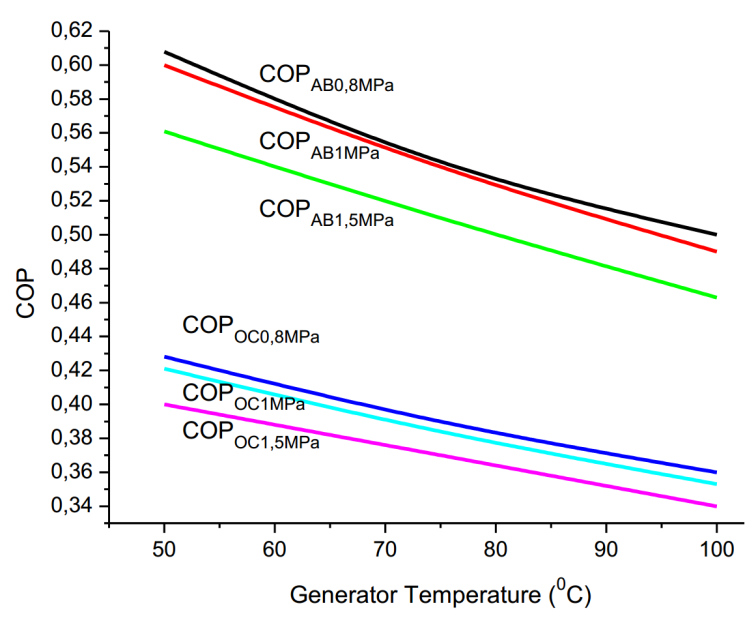

Fig. 3. Variation of COP with generator temperature for different pump pressure.

The description, the fluid, the concentration, the mass flow rate, the phase, the pressure, the temperature, the enthalpy, and the energy of each streams of the cycle are given in Table II for $75^{\circ} \mathrm{C}$ generator heat temperature and for $1 \mathrm{MPa}$ pump pressure. Also the heat energies of the evaporator 1 , the absorber, the condenser 2 , the compressor and the generator are given. In addition 


\section{TABLE II}

Thermodynamic properties of the streams of the compression-absorption cascade refrigeration system for $75^{\circ} \mathrm{C}$ generator heat temperature and $1 \mathrm{MPa}$ pressure. saa — strong aqua-ammonia, waa — weak aqua-ammonia, shtv — super heated vapor.

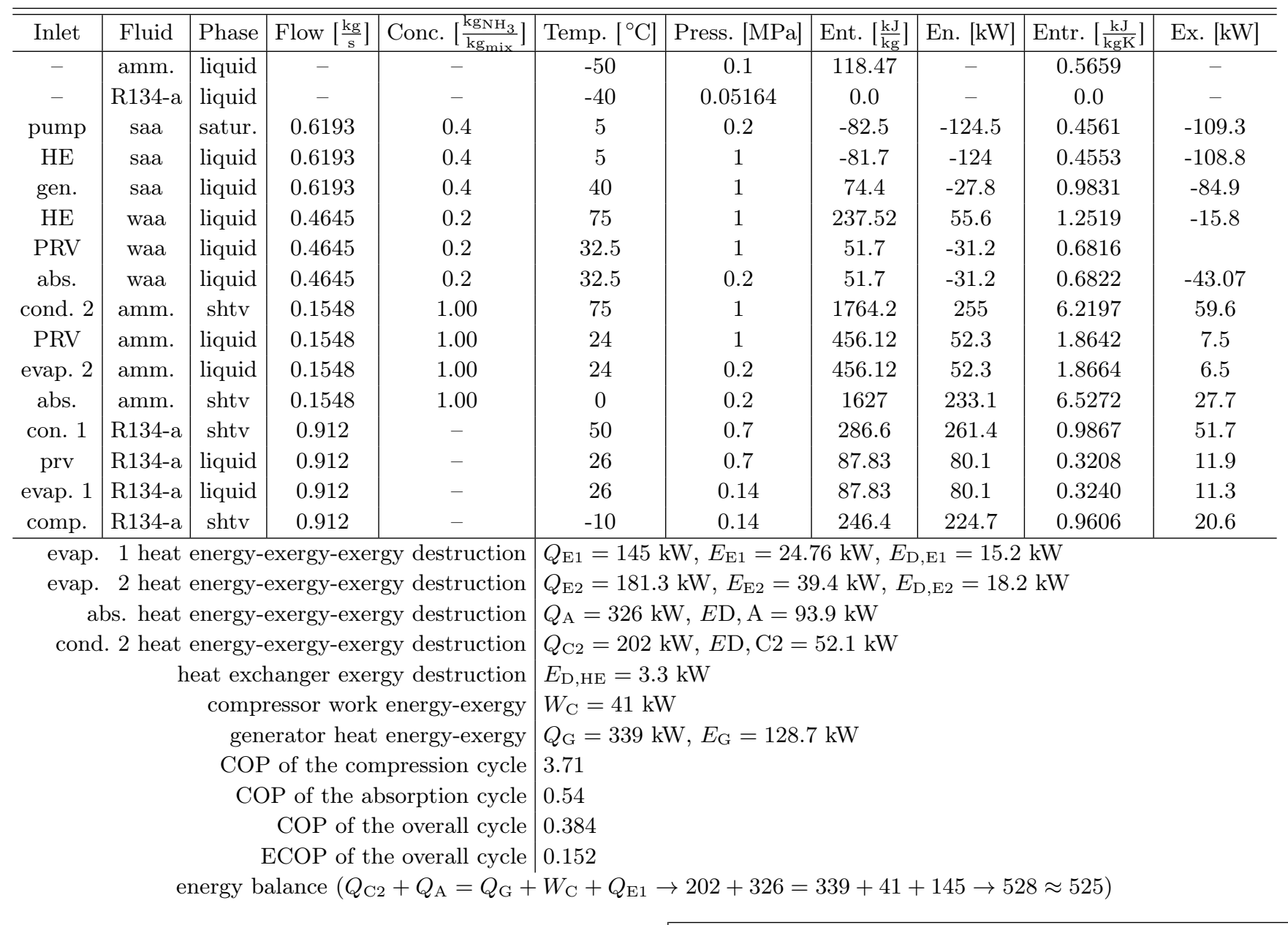

the COP of the absorption cycle is found as 0.54 and the COP of the overall cycle is found as 0.384 and the coefficient of performance of the compression cycle is found as 3.71 for $75^{\circ} \mathrm{C}$ generator heat temperature and for $1 \mathrm{MPa}$ pump pressure.

In Fig. 2 variations of energy with pressure of the cycle for $75^{\circ} \mathrm{C}$ temperature of the generator are given. In Fig. 2, as can be seen, increase of the pump pressure decreases the work needed for the compressor. In addition the heat given to the generator decreases with increase of the pump pressure. Also increase of the pump pressure decreases the condenser 2 and evaporator 1 heat energies.

In Fig. 3 variation of COP of the absorption and the overall cycles with generator temperature are given. It can be concluded that increase of the generator temperature decreases the COP of the absorption and the overall cycles. Also decrease of the pump pressure increases the COP of the absorption and the overall cycles.

In Fig. 4 variations of the energies with generator temperature for different pump pressures are given. It can be concluded that increase of the generator temperature increases the generator inlet heat, the absorber outlet heat and the condenser 2 outlet heat energies. Also it can be seen that increase of the pump pressure decreases the generator inlet, the absorber outlet and the condenser 2 outlet heat energies.

In Fig. 5 variations of exergetic coefficient of performance with generator temperature for different pump pressures are given. It can be concluded that increase of pump pressure and the generator temperature decreases the exergetic coefficient of performance. The reason is that increase of the generator temperature increases the condenser outlet temperature that decreases the ECOP.

In Fig. 6 variations of the exergies of the components of the cycle with generator temperature for different pump pressures are given. It can be concluded that increase of the generator temperature and pump pressure increases the generator inlet exergy. The evaporator 2 exergy is not dependent on the generator temperature however 


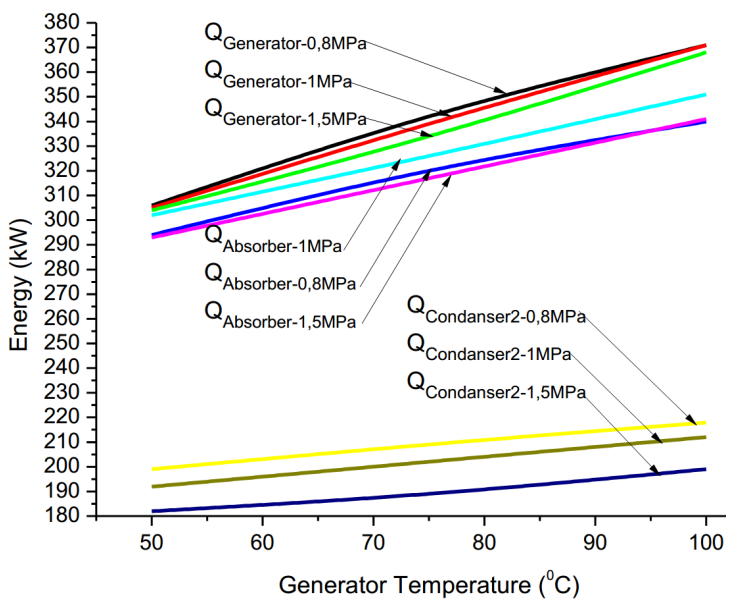

Fig. 4. Variations of energy with generator temperature for different pump pressure.

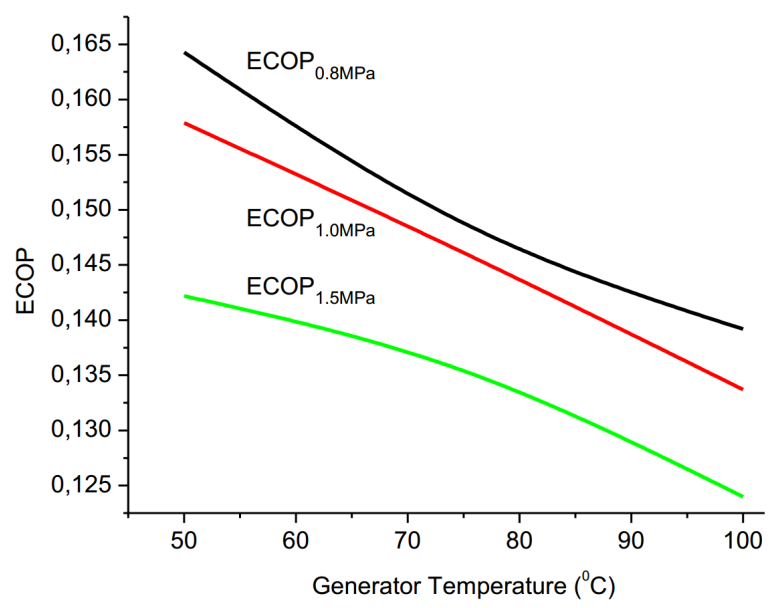

Fig. 5. Variation of exergetic coefficient of performance with generator inlet heat temperature for different pump pressure.

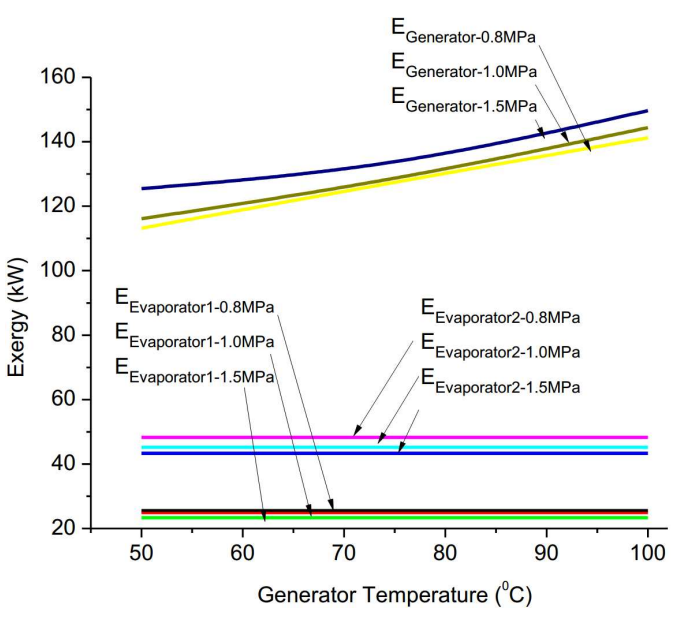

Fig. 6. Variation of the exergy of the components of the cycle with generator temperature for different pump pressure.

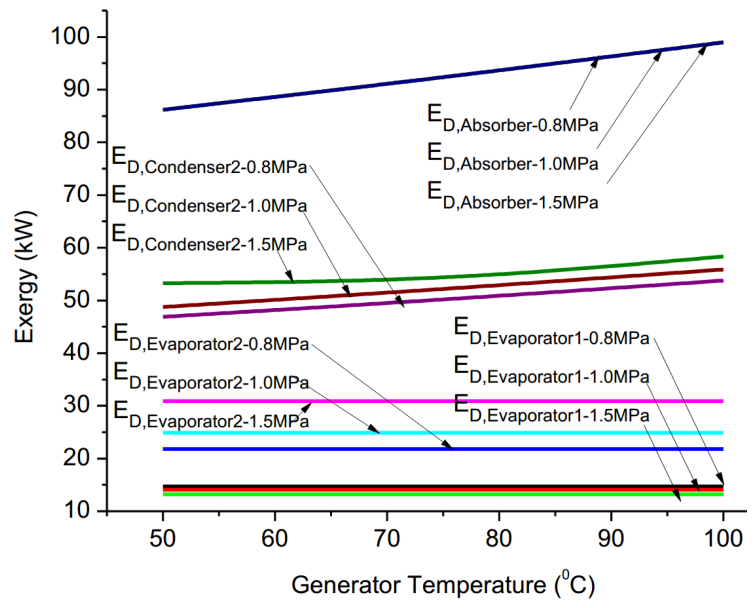

Fig. 7. Variation of destructed exergy of the components of the cycle with generator inlet heat temperature for different pump pressure.

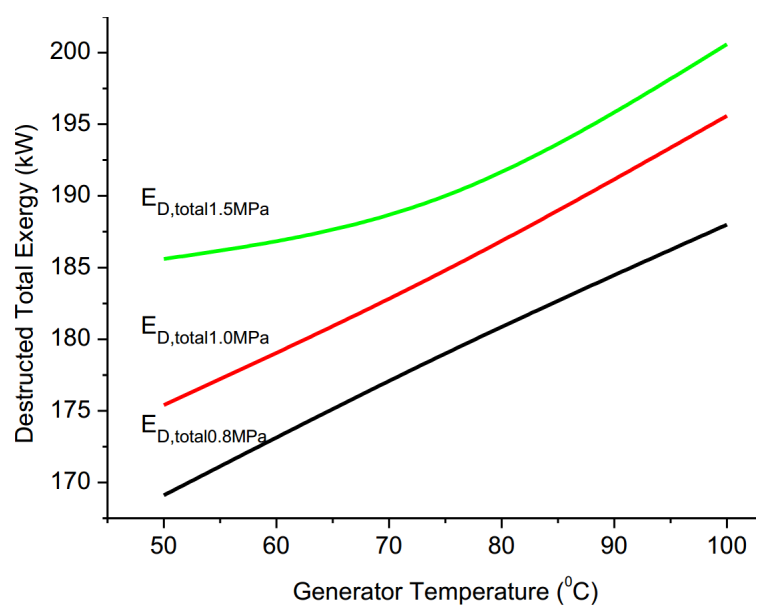

Fig. 8. Variation of destructed total exergy of the cycle with generator inlet heat temperature for different pump pressure.

increase of the pump pressure decreases the exergy of this component. The same thing is valid for the evaporator 1 . The reason is the evaporator 2 outlet temperature and inlet pressure is taken constant, and also for evaporator 1 inlet and outlet temperature and inlet-outlet pressure is taken constant.

In Fig. 7 variations of the destructed exergies of the components of the cycle with generator inlet heat temperature for different pump pressures are given. As can be seen, the pump pressure is not effective on destructed exergy of the absorber, but increase of the generator temperature increases the destructed exergy of the absorber. Increase of the pump pressure increases the destructed exergy of the evaporator 2 and decreases the destructed exergy of the evaporator 1 . It can be seen that increase of the generator temperature does not affect the destructed exergy of the evaporator 2 and evaporator 1 . The reason 
is the evaporator 2 outlet temperature and inlet pressure is taken constant, and also for evaporator 1 inlet and outlet temperature and inlet-outlet pressure is taken constant.

In Fig. 8 variations of destructed total exergies of the cycle with generator inlet heat temperature for different pump pressures are given. It is concluded that increase of the generator temperature and the pump pressure increases the destructed total exergy of the cycle.

\section{Conclusion}

There is a need for cooling by using the waste heat energy in food industry. The thermodynamic analysis of the compression-absorption cascade refrigeration systems is obtained. The generator temperature is taken as 50,75 , and $100^{\circ} \mathrm{C}$ which is the compression-absorption cascade cooling cycle appropriate for most of the kind of waste heat applications. Increase of the pump pressure decreases the heat given to the generator. Also increase of the pump pressure decreases the condenser 2 and evaporator 1 heat energies and the $\mathrm{COP}$ of the absorption and the overall cycles. Increase of the generator temperature decreases the COP of the absorption and the overall cycles. Increase of the generator inlet heat temperature increases the generator inlet heat, the absorber outlet heat and the condenser 2 outlet heat energies. The power spends for the cooling systems can be decreased by about $30-50 \%$ by using this waste heat in absorption cooling system integrated with refrigeration systems.

Increase of the pump pressure and the generator temperature decreases the exergetic coefficient of performance. The reason is that increase of the generator temperature increases the condenser outlet temperature that decreases the ECOP. Increase of the generator temperature and pump pressure increases the generator inlet exergy. It is concluded that increase of the generator temperature and the pump pressure increases the destructed total exergy of the cycle.

\section{References}

[1] J.A. Dopazo, J.F. Seara, J. Sieres, F.J. Uhia, 10.1016/j.applthermaleng.2008.07.006 Appl. Therm. Eng. 29, 1577 (2009).

[2] D. Sun, En. Convers. Manag. 39, 357 (1998).

[3] J.F. Seara, J. Sieres, M. Vazquez, Appl. Therm. Eng. 26, 502 (2006).

[4] C. Cimsit, I.T. Ozturk, Appl. Therm. Eng. 40, 311 (2012).

[5] V. Jain, S.S. Kachhwaha, G. Sachdeva, En. Convers. Manag. 75, 685 (2013).

[6] V. Jain, G. Sachdeva, S.S. Kachhwaha, En. Convers. Manag. 93, 49 (2015).

[7] V. Jain, G. Sachdeva, S.S. Kachhwaha, B. Patel, En. Convers. Manag. 113, 230 (2016).

[8] Y. Xu, F. Chen, Q. Wang, X. Han, D. Li, G. Chen, Appl. Therm. Eng. 75, 504 (2015).

[9] Y. Chen, W. Han, H. Jin, Appl. En., available online December, 2015.

[10] M. Mehrpooya, M. Omidi, A. Vatani, Appl. Therm. Eng. 98, 591 (2016).

[11] D. Sun, Appl. Therm. Eng. 17, 211 (1997).

[12] R. Tillner-Roth, D.G. Friend, J. Phys. Chem. Ref. Data 27, 63 (1998).

[13] K. Annamalai, I.K. Puri, Advanced Thermodynamics Engineering, CRC Press LLC, 2002.

[14] I. Dincer, M.A. Rosen, Exergy, Energy, Environment and Sustainable Development, 1st ed., Elsevier, 2007. 